CZU:811.135.1'367.625

https://doi.org/10.52505/filomod.2021.15.13

\title{
VERBE CU PREDICAȚIE INCOMPLETĂ ÎN LIMBA ROMÂNĂ
}

\author{
ELENA CONSTANTINOVICI \\ Institutul de Filologie Română „B. P.-Hasdeu” al MEC
}

\begin{abstract}
Rezumat. Articolul tratează problema verbelor care nu pot îndeplini funcția de predicat fără compliniri suplimentare. E vorba de verbele cu predicație incompletă a căror schema sintactico-valențială este completată de elemente care, în general, $n u$ sunt obligatorii pentru caracterizarea subiectului. Din această categorie, fac parte, după cum se știe, circumstanțele. Cu toate acestea, unele verbe includ circumstanțele in structura lor actanţială, atribuindu-le un statut asemănător cu cel al rolurilor actanțiale. Acest fapt e determinat de insuficiența semantică a lexemelor verbale. Cel mai frecvent apar în această poziție circumstanțialele de loc, urmate de cele instrumentale, cele de timp, de mod, de cauză etc.
\end{abstract}

Cuvinte-cheie: predicație, funcție, verb, actant, circumstanțe, schemă sintactică.

Abstract. The article deals with the problem of verbs that cannot fulfill the function of predicate without additional fulfillments. These are verbs with incomplete predication whose syntactic-valence scheme is complemented by elements that, in general, are not mandatory for characterizing the subject. As is well known, circumstances are part of this category. However, some verbs include circumstances in their actantial structure, giving them a status similar to that of actantial roles. This fact is determined by the semantic insufficiency of verbal lexemes. The most frequently appear in this position are the circumstantial of place, followed by the instrumental, the temporal, the modal, the causal etc. scheme.

Keywords: predication, function, verb, actant, circumstances, syntactic

Predicația (sau predicativitatea) poate fi definită ca un raport sintactic stabilit între grupul subiectului și cel al predicatului pentru a constitui un enunț. $\mathrm{Cu}$ alte cuvinte, predicația este o relație dintre 2 funcții: de identificare (a subiectului) și de descriere (a predicatului). Deci cele două constituente ale nivelului predicativ - subiectul și predicatul - au funcții diferite: subiectul are funcția referențială, de identificare a unui obiect din realitate, despre care se va spune ceva cu ajutorul predicatului. Predicatului îi revine funcția comunicativă de caracterizare a obiectului ales pentru a alcătui un enunț. Verbul care exprimă predicatul spune ceva despre subiect, dar nu de unul singur. De cele mai multe ori, el înglobează toate elementele care caracterizează subiectul dintr-un anumit enunț, elemente 
care se numesc determinanți. Asta pentru că „,predicatul logico-sintactic este partea componentă a enunțului organizată în jurul unui verb. El este constituit din verbul centru împreună cu toți determinanții verbului, care, indiferent de natura relației și de gradul de coeziune față de centru, aduc o informație importantă pentru caracterizarea obiectului comunicării” (Bărbuță, p. 83). Numărul de determinanți este prevăzut de structura actanțială a verbului care cuprinde vecinătăţile actanţiale cu matricea de roluri tematice obligatorii, caracteristice pentru relaţiile actanţiale sau circumstanţiale ale unui verb. Aceste tipuri de relaţii semantice reprezintă situaţiile şi participanţii implicaţi.

Mutatis mutandis, teoria solidarităţilor lexicale, elaborată de Eugen Coșeriu, indică un fapt asemănător care are loc la nivel lexical. Uneori cuvintele se presupun unele pe altele datorită structuii lor semantice, formând perechi lexicale: a lătra - câine, a necheza - cal, a înflori - plantă, a doborî-copac (Coșeriu, p. 8). Mai multe relații de tipul acesta au fost relevate în literatura de specialitate. De exemplu, obiectul şi însuşirea lui permanentă (zahăr - dulce, lămâie - acru, zăpadă - alb, iarbă - verde, lamă - ascuţit etc.); acţiunea şi agentul ei (a lătra - câine, a mieuna - pisică, a scrie - scriitor, a cumpăra - cumpărător etc.); acţiunea şi instrumentul ei (a mătura - mătură, a tăia cuţit, a ara - plug, a pieptăna - pieptene etc.); acţiunea şi locul desfăşurării ei (a dormi - pat, a şedea - scaun, a merge - drum, stradă, a învăţa-şcoală etc.); acţiunea şi cauzatorul ei ( $a$ vedea - a arăta, a arde - a aprinde, a avea - a da etc.) (Constantinovici, p. 241-242). Eugen Coșeriu menționa într-una din conferințele sale că unele cuvinte (se referea la cuvintele care denumesc părțile corpului) nu pot fi utilizate fără determinanți. Nu poți spune *Am văzut o femeie cu picioare. sau *Un copil cu ochi se uita la mine. Trebuie să spunem cum erau picioarele (frumoase, drepte, strâmbe) sau ochii (mari, albaștri, negri, plânși etc.).

Să examinăm următoarele enunțuri, care reprezintă toate tipurile de valență a verbului:

(1) Fulgeră. (2) Câinele mușcă. (3) Un elev a abandonat școala. (4) Copiii i-au dăruit profesoarei flori. (5) Noi am arendat un spațiu pentru birou de la prietenii noștri pe un termen de un an.

Dacă am încerca să eliminăm măcar un singur determinant din aceste enunțuri, ele ar fi incomplete. Sunt însă cazuri, când, pe lângă garnitura de determinanți strict obligatorii, verbul are nevoie și de alte compliniri pentru a exprima plenar enunţul.

În literatura de specialitate este unanim recunoscut faptul că actanții și circumstanțele ocupă locuri diametral opuse în structura actanțială a verbului. Dacă actanții, fiind implicați obligatoriu în procesul exprimat de verb, necesită exprimare explicită, circumstanțele, de obicei, au un rol secundar în conturarea situației din realitate, din care cauză capătă o prezență facultativă în structura sintactico-valențială a verbului. De obicei, actanții sunt considerați 
constituenți interni, adică poziții regizate de verb, cu prezență obligatorie în formula sintactică a verbului, iar circumstanțele, constituenți externi, care nu fac parte din structura sintactică a verbului. Cercetările ulterioare au stabilit că ,şi printre circumstanţe pot fi delimitaţi constituenţi interni, care constituie poziţii regizate de verb şi sunt, de regulă, incluşi în structura actanţială a verbului, şi constituenţi externi care nu ţin de formula sintactică a verbului. Caracterul facultativ sau obligatoriu al circumstanțelor este legat de specificul semantico-valenţial al verbului." (Constantinovici, p. 239)

Astfel, verbele intranzitive sunt monovalente și construiesc enunțuri complete fără determinanți: Lumânarea arde., Copiii aleargă., Copacii inverzesc. Există însă și verbe intranzitive care necesită determninări pentru a completa predicatul și a înțelege enunțul. De exemplu, verbele: a apărea, a crește, a deveni, a fi, a se intoarce etc. au nevoie de un determinant în plus pentru a alcătui un predicat care să caracterizeze subiectul mai bine: Mașina apare de după colț. Iarna se întunecă repede. Venitul crește vertiginos. Satul se află în vale. Fără acești determinanți circumstanțiali, enunțurile ar fi mai greu de înțeles. Anume în aceste cazuri se vorbește despre o predicație incompletă. $\mathrm{Cu}$ alte cuvinte, o predicație ,,este incompletă atunci când propoziția al cărei predicat nu are un înțeles deplin decât dacă este însoțit de una sau mai multe compliniri (determinanți) care îi precizează și îi întregesc sensul. Complinirea sau complinirile verbului se află în raporturi condiționate cu verbul, prezența lor decurgând ca o necesitate din semantica lui." (Sandulescu, Vianu; Volumul 4, Preda, p. 351-352). Astfel de cazuri se atestă în toate clasele sintagmatice de verbe. Verbele tranzitive sunt bivalente, structura lor este completă cu o singură complinire, dar unele verbe tranzitive necesită, pe lângă un complement direct obligatoriu, și alte complemente pentru a-și completa semnificația. De exemplu, verbul a denumi este tranzitiv, al cărui sens este $<\mathrm{A}$ da un nume $>$, iar schema sa actanțială este: $\mathrm{N}_{1}+\mathrm{V}+\mathrm{N}_{2}+\mathrm{N}_{3}$

$\checkmark$ A denumi pe cineva / ceva: un obiect, un fenomen.

- Specialiștii denumesc acest produs geam termoizolant. Cercetătorii denumesc acest fenomen iluzia controlului. Părinții au numit-o Ana. Colectivul $l$-a ales pe Ion președinte.

În cazul acesta, cel de-al doilea determinant nu caracterizează subiectul, ci complementul direct. De aceea în gramatici este cunoscut ca un complement al obiectului. La fel e și în cazul verbelor dublu tranzitive. În unul din sensurile sale $<$ A chestiona, a examina $>$, verbul $a$ intreba reclamă 2 compliniri pentru a exprima plenar situația de comunicare, având schema: $\mathrm{N}_{1}+\mathrm{V}+\mathrm{N}_{2}+\mathrm{N}_{3}$

$\diamond \mathrm{A}$ întreba pe cineva ceva: pe elevi cuvintele, pe un student temele la examen, pe un trecător drumul spre gară etc.

- Profesorul îl întreabă pe elev tema.

În limba română există mai multe verbe cu predicație incompletă. După cum am arătat mai sus, sunt verbe care necesită actanți suplimentari pentru a suplini pozițiile deschise. Dar sunt și verbe care necesită implicarea obligatorie 
a circumstanțelor, cel puțin, în unul sau două sensuri ale sale. Anume aceste verbe sunt mai interesante din punctul de vedere al predicației incomplete. De exemplu, a se afla, a apărea, a proveni, a depinde, a pretinde, a locui etc. deschid anumite poziţii libere pentru circumstante care neapărat trebuie ocupate, în caz contrar, enunţul va rămâne incomplet, neterminat: *Mașina apare. *Satul se află. *El locuieşte. etc. După cum e lesne de observat, în aceste contexte circumstanţele sunt obligatorii pentru plenitudinea semantică a enunţului.

În continuare, vom analiza câteva verbe cu predicație incompletă, a căror structură actanțială include circumstanțialele pe poziții obligatorii. Dintre toate circumstanțele, complementul circumstanțial de loc apare cel mai des ca fiind obligatoriu. La o primă selecție, au fost identificate următoarele verbe cu circumstantial de loc obligatoriu fie integral, fie partial, doar la anumite sensuri: a se afla, a ajunge, a se arăta, a se arunca, a așeza, a se aşeza, a se concentra, a coborî, a se coborî, a da, a se deplasa, a se depărta, a depozita, a depune, a dispărea, a se duce, a fi, a ieşi, a se instala, a intra, a încuia, a se îndrepta, a innopta, a se juli, a se lega, a locui, a se muta, a proveni, a se situa, a se stabili etc. După cum e lesne a observa, verbele selectate sunt fie intranzitive, fie tranzitive, fie pronominale. Schema sintactico-valențială a verbelor intranzitive

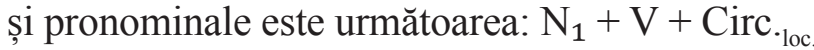

A se aşeza v. pron.

1. A lua loc, a se pune.

$\diamond$ Cineva se aşază: pe scaun, pe canapea, pe pat, în fotoliu, pe covor, pe podea, în bancă, pe pământ, pe iarbă, la soare, la umbră, sub un copac, la fereastră, lângă cineva, pe locul său, pe locul altuia, la masă, alături, jos.

- Toți elevii s-au aşezat în bănci. M-am aşezat în fotoliu. Îmi permiteți să mă aşez lângă dumneavoastră?

2. A se lăsa din zbor.

- Pasărea s-a aşezat pe o creangă. Albinele se aşază pe flori. Porumbelul s-a aşezat pe pervazul ferestrei. Un stol de păsări se aşază în teiul bătrân.

A coborî v. intr.

1. A se da jos, a se deplasa în jos.

$\checkmark$ A coborî: din copac, din maşină, dintr-un vehicul, din autobuz, din tren, de pe cal, de pe acoperiş, de pe munte, la subsol, în stradă, în pivniţă, în mină, în peşteră, la vale, pe pământ, pe mal, pe ţărm, pe o insulă, pe uscat, pe scări, pe trepte.

- Turmele coboară de pe munte la iernat. Un domn a coborât grăbit pe scări. Coborâți la prima (staţie). Eu cobor la staţia terminus.

2. A apune.

- Soarele coboară către asfinţit / spre apus /spre orizont. Soarele a coborât după deal / după munte.

3. A fi orientat în jos.

- Drumul coboară spre câmpie. Cărarea a inceput să coboare către baza muntelui. Panta coboară pieziş. 
4. A se lăsa, a cădea.

- Noaptea coboară peste oraş. Peste câmpie a coborât ceaţa.

A fi v. intr.

A se afla, a se găsi.

$\diamond$ A fi: acasă, pe stadion, la facultate, în oraş, în provincie, la ţară, la munte, la mare, din Moldova, în străinătate.

- Aici sunt, aici rămân. El este în clasă. El nu e aici. El e din București. Maşina e in garaj. Cheile sunt în uşă. Cartea este pe masă. Casa e pe malul unui lac. El este cu prietenii săi. Cine e acolo? Cine e aici? Din ce loc eşti? Unde aţi fost?

A ieşi v. intr.

1. A trece din interior în exterior; a părăsi.

$\diamond$ A ieşi: din cameră, din casă, din spital, din închisoare, în stradă, în grădină, în parc, în oraş, pe poartă, pe uşă la tablă, la aer, la pădure, la iarbă verde, la plimbare, la cumpărături, la vânătoare.

- Trenul iese încet din gară. Doctorul i-a dat voie să iasă afară. Mingea a ieşit din teren. Maşina a ieşit din tunel. Foamea îl face pe lup să iasă din pădure. Râul a ieşit din matcă.

2. A se ivi, a apărea, a se face văzut sau auzit.

$\diamond$ A ieşi: la iveală, la lumină, din nori.

- Avionul a ieşit din nori. Cartea a ieşit săptămâna trecută. Adevărul a ieşit din gura copiilor.

3. A părăsi o stare, o situaţie, o împrejurare.

$\diamond$ A ieşi: la pensie, la lucru, din partid, din serviciu, din rând, din joc, din încurcătură, din necaz, dintr-un impas, din starea de șoc, din starea de criză, din uz.

- Abia am ieşit din iarnă. Bolnavul a ieșit din comă. Ion se zbate să iasă din sărăcie.

A se instala v. pron.

A se aşeza, a se stabili într-un loc.

$\diamond$ A se instala: într-un nou apartament, într-un oraş, într-un han, într-un hotel, la un hotel, în locuinţă nouă, într-un fotoliu, într-un post, într-o meserie, la cineva ca la el acasă.

- Ei s-au instalat de mult în acest apartament. Se instalase în faţa lui şi-l măsura cu privirea. S-a instalat la noi şi n-a mai plecat.

A intra v. intr.

1. A trece din afară înăuntru.

$\diamond$ A intra: înăuntru, în casă, în cameră, într-un birou, într-un imobil, în mănăstire, într-o ţară, pe o stradă laterală, tot mai adânc în pădure, în inima pădurii, în apă, pe ușă, pe fereastră.

- Profesorul a intrat în clasă. Trenul intră în gară. Vasul intră în port. Hoțul a intrat pe fereastră. Trupele duşmane au intrat în oraş. Fumul intră în 
casă. Lumina intră prin geamurile mari. Nu puteți intra acolo. Sărăcia intră pe uşă şi dragostea iese pe fereastră.

A se îndrepta v. intr.

A porni într-o anumită direcţie, a se orienta.

$\diamond$ A se îndrepta: spre casă, spre uşă, spre pădure, spre sud, spre nord, spre un loc, într-acolo, către cariera de profesor, către prăpastie, spre dezastru, către o catastrofă.

- Băiatul s-a îndreptat către geam. Trenul se îndreaptă spre graniţa. Pasagerii s-au îndreptat spre ieșire. Toate privirile s-au îndreptat spre noi.

A lucra v. intr.

A munci.

$\diamond$ A lucra: la fabrică, la uzină, la întreprindere, la căile ferate, la o companie, la o firmă, la un ziar, la televiziune, la vamă, pe un vas fluvial, pe câmp, în producţie, în port, în cercetare, la domiciliu.

- Tipul ăsta lucrează într-o bancă.

A (se) opri v. intr.

A sta pe loc.

$\diamond$ A opri: în fața casei, la semafor, la intersecţie, la marginea şoselei, la trecerea pe calea ferată. drumului.

- Acceleratul nu opreşte în această staţie. Taxiul a oprit în mijlocul

$\diamond$ A se opri: lingă uşă, lângă cineva, în drum, la jumătatea drumului, la mijlocul drumului, la colţul străzii, la marginea trotuarului, pe pod, într-un port // din mers, din drum.

- Ne vom opri la restaurantul de pe traseu. Convoiul s-a oprit pe câmp deschis pentru un popas de noapte. Trenul s-a oprit în stație.

Schema sintactico-valenţială a verbelor tranzitive cu complement circumstanțial de loc obligatoriu este următoarea: $\mathrm{N}_{1}+\mathrm{V}+\mathrm{N}_{2}+$ Circ. $_{\text {loc. }}$

Verbele următoare (în unul sau în câteva din sensurile sale) reclamă 2 compliniri, una actanțială, iar alta circumstanțială (în cazul discutat aici circumstanțial de loc)

A așeza v. tr.

A pune.

$\diamond$ A aşeza pe cineva / ceva: un copil, elevii, oaspeţii pe scaun, în bănci, la mese.

- Invăţătoarea i-a aşezat pe elevi în bănci. Au aşezat dulapul lângă perete. Chelnerul aşază tacâmul lângă farfurie.

\section{A coborî v. tr.}

A da jos.

$\checkmark$ A coborî ceva: un sac, o ladă, un geamantan, un bolnav pe scară, storurile, cortina, steagul, pânzele // din pod, din căruţă, din maşină.

- Unchiul a coborât sacii din căruţă. Dan și-a coborât lucrurile la intrare. 
A da v. tr.

A arunca, a azvârli, a pune, a băga.

$\checkmark$ A da pe cineva / ceva: cana, hainele vechi // afară, deoparte, de pământ, la coş, la gunoi, la fier vechi.

- Bunica a dat pâinea în cuptor. Ciobanii au dat oile în luncă. Bărbatul a oftat și și-a dat pălăria pe ceafă. Să dai oglinda asta spartă la gunoi. Dă-l afară!

\section{A depune v. tr.}

1. A lăsa un obiect din mână, punându-1 undeva; a prezenta; a face; a renunţa.

$\diamond$ A depune ceva: paltonul și pălăria la garderobă, valizele la casa de bagaje, o coroană pe un mormânt.

- Președintele a depus o coroană de flori la monumentul eroilor căzuți în război. Un bărbat necunoscut a depus o bombă în vagonul trenului accelerat.

2. A preda, a înregistra un act (în vederea unei proceduri).

$\diamond$ A depune ceva: o carte la bibliotecă, un document la arhivă, bani la o bancă, o cerere de angajare, un formular de înscriere la universitate, un proiect de lege în parlament.

- El își depune banii câștigați la bancă. Familiile lor au depus deja plângere la poliție. Putem depune o scrisoare în instanță.

\section{A duce v. tr.}

A îndrepta, a conduce spre...

$\checkmark$ A duce pe cineva undeva: pe un copil la școală, la plimbare, în oraş, la un medic; pe un cunoscut acasă, la gară, la aeroport; pe un infractor la închisoare; turiștii la hotel; ostaşii la luptă; caii la adăpat; turmele la păscut.

- I-am dus pe copii la școală. L-am dus într-un loc sigur. Te vom duce la șeful nostru. Polițiștii l-au dus pe întemnițat în celulă. Voi duce barcă la mal. Dacă te iei după măgar, te duce la stână.

\section{A încuia v. tr.}

1. A păstra sub cheie.

$\diamond$ A încuia ceva: bijuteriile într-un dulap, banii în safeu, lucrările în birou.

2. A reţine închis într-o încăpere.

$\diamond$ A încuia pe cineva: în odaie, în subsol, în pivniță, în pod, în camera lui, într-o cabină telefonică.

- L-au încuiat în odaie. Hoții i-au încuiat pe paznici în încăperea lor. Când au plecat din casă dimineața, părinții l-au încuiat pe copil înăuntru. L-au încuiat în camera lui.

\section{A uita}

A lăsa involuntar.

$\diamond$ A-şi uita ceva undeva: mănuşile, cartea, banii, umbrela în autobuz // acasă, în clasă, undeva

- Elevul şi-a uitat caietul de matematică acasă.

Celelalte circumstanțe apar mai rar în această poziție. Complementul circumstanțial de timp este obligatoriu la o serie de verbe intranzitive a căror 
schemă semantico-valenţială este: $\mathrm{N}_{1}+\mathrm{V}+\mathrm{Circ}_{\text {timp, }}$, ca, de exemplu: a fi, a se naşte, precum și tranzitive $a$ aștepta, a lăs $a$ a căror schemă este: $\mathrm{N}_{1}+\mathrm{V}+\mathrm{N}_{2}$ + Circ. timp $_{\text {. }}$

A fi v. intr.

A se întâmpla, a se petrece.

- Ultimul cutremur mare a fost în martie 1977. Vernisajul va fi mâine. Premiera e astă-seară.

A lăsa v. tr.

A amâna, a păsui, a aştepta.

$\checkmark$ A lăsa ceva: pe mâine, pe a doua zi, pe altă dată, pe mai târziu, de pe o zi pe alta.

- Vom lăsa decizia asta pentru următoarea ședință. Am convenit să lăsăm pe altă dată discuția. Nu lăsa pe mâine ceea ce poți face astăzi. Lucrul de seară nu-l lăsa pe dimineață.

A ține v. intr.

A dura, a dăinui.

- Spectacolul a ţinut două ore. Ploaia a ţinut o săptămână. Furtuna nu va ţine mult. Proviziile ţin pentru o săptămână. Prietenia lor nu a ţinut mult. Din păcate, fericirea ei nu ține o veşnicie. Tradiţia asta ţine de secole. Atâta ține pacea, cât vrea vecinul. Piatra ţine mai mult ca lemnul. Cât o să mai ţină oare frigul acesta?

Schema semantico-valentială a verbelor care reclamă obligatoriu un complement circumstanțial de mod este următoarea: $\mathrm{N}_{1}+\mathrm{V}+$ Circ. $_{\text {mod }}$ Din această clasă fac parte verbele : a se aprinde, a arăta, a se comporta, a costa, a se majora, a se purta, a proceda, a se reduce, a se ridica etc.

A se aprinde v. pron.

(fig.) A se înflăcăra.

$\checkmark$ Cineva se aprinde: ușor, repede.

- Șeful meu se aprinde repede. Tipul se aprinde ușor.

A costa v. intr.

A avea valoare de...; a se obţine cu preţul.

$\diamond$ A costa: bani, o grămadă, o grămadă de bani, o groază de bani, o sumă frumușică, o avere / mai nimic, scump, ieftin, mult, puţin.

- Cartea costă trei lei. Costumul costă o mie de lei. Mașina a costat o groază de bani. Timpul costă bani. Treaba asta va costa mai mulți bani. Anularea contractului ar costa o avere. Totul costă bani. Aceasta costă ceva mai scump. Rochia aceasta nu costă mai nimic.

A se desfășura v. pron.

A decurge, a evolua.

$\diamond$ A se desfăşura: bine, normal, conform planului, fără niciun incident, fără accidente, fără necazuri, fără dificultăţi, cu succes, cum trebuia.

- Evenimentele se desfăşoară normal. Experimentul s-a desfășurat conform planului. Programul se desfăşoară fără dificultăţi. Operațiunea s-a 
desfășurat fără pregătire suficientă. Audierea s-a desfășurat într-o atmosferă de dezacord exprimat între părți. Al doilea tur al alegerilor s-a desfășurat intr-un mod regretabil. Totul s-a desfăşurA se exprima v. pron. A reda prin cuvinte; a vorbi.

$\diamond$ A se exprima: corect, confuz, pretenţios, bombastic, eufemistic, vulgar, cu uşurinţă, cu dificultate, cu eleganţă, cu dispreţ, printr-un zâmbet, în cuvinte, în dialectul local, în termeni moderaţi, în termeni delicaţi, în alegorii, nefavorabil la adresa cuiva.

- Ea se exprimă corect în limba română. Lor li se interzice în mod sistematic dreptul de a se exprima liber. Minoritătile au dreptul de a se exprima în limba lor maternă.

A gândi v. intr. A medita, a judeca.

$\diamond$ A gândi: corect, greşit, lucid, logic, sănătos, pozitiv, raţional, neconvenţional, serios, profund, intens, bine, mai pe îndelete, în sinea sa, cu glas, cu voce tare, în imagini, în clişee.

- Trebuie să gândim atent, inteligent. Gândim mai clar când ascultăm muzică. Trebuie să gândim cu mintea limpede. Nu suntem instruiți sa gândim astfel. Facem antrenamentul ca să gândim altfel. În rest noi doi gândim la fel. Gândeşte întâi, apoi vorbeşte. El gândește una şi spune alta.

A înota v. intr. A înainta în apă prin înot.

$\checkmark$ A înota: ca un peşte, pe spate, sub apă, contra curentului, spre mal.

- Naufragiatiii au înotat spre insulă. Nimeni nu poate înota atât de departe. Peștii înoată împotriva curentului.

Și complementul circumstanțial de cauza apare pe poziție obligatorie pe lângă unele verbe, care alcătuiesc enunțuri având structura: $\mathrm{N}_{1}+\mathrm{V}+$ circ. de cauză.

A se aprinde (fig.) A se înflăcăra.

$\diamond$ Cineva se aprinde: de dor, de dragoste, de pasiune, de bucurie.

Tinerii se aprind de pasiune.

A se consuma v. pron.

A se epuiza.

- Ea se consumă de prea mult efort. Vecinii se consumă din cauza unei vechi dușmanii.

A fierbe v. intr. cu sensul (fig.) A fi într-o stare de mare agitaţie.

$\diamond$ A fierbe: de necaz, de nerăbdare, de indignare, de mânie, de furie.

- Ion fierbea de ciudă. Fierbe în el sângele de mânie.

Complementul circumstantial instrumental a fost analizat din acest punct de vedere într-un alt studiu (Constantinovici, p. 241-244).

O serie de verbe cumulează mai multe complemente circumstanțiale pentru a caracteriza mai precis subiectul. Una dintre cele mai frecvente combinații este reprezentată de schema: $\mathrm{N}_{1}+\mathrm{V}+$ Circ. $_{{ }_{\text {loc. }}}+$ Circ $_{{ }_{\text {mod. }}}$ De exemplu: 
A dispărea v. intr.

A ieşi din câmpul vizual; a nu mai fi actual.

$\checkmark$ Cineva / ceva dispare: din vedere, în întuneric, în ceaţă, în mulţime, în depărtare, înăuntru, după cotitură, după colină, la orizont, dincolo de linia orizontului, de pe scena politică // brusc, treptat, pe neobservate, pe neașteptate, ca prin farmec.

- Ion a dispărut pe neobservate de la petrecere. Hoțul a dispărut brusc din vedere. Mulți politicieni dispar treptat de pe scena politică.

\section{A ieși v. intr.}

1. A trece din interior în exterior; a părăsi.

$\diamond$ A ieşi: din cameră, din casăa, din spital, din închisoare, în stradă, în grădină, în parc, în oraş, pe poartă, pe uşă, la tablă, la aer, la pădure, la iarbă verde, la plimbare, la cumpărături, la vânătoare. / pe furiș.

- Copilul a ieșit pe furiș din casă.

A intra v. intr.

1. A trece din afară înăuntru.

$\checkmark$ A intra: înăuntru, în casă, în cameră, într-un birou, într-un imobil, în mănăstire, într-o ţară, pe o stradă laterală, tot mai adânc în pădure, în inima pădurii, în apă, pe uşă, pe fereastră. // prin efracţie, cu forţa, repede, valvârtej, ca o furtună, ca o vijelie, agale, pe furiş, pe dibuite, în treacăt, pentru câteva minute, tropăind.

- Bunicul intră tropăind în casă. Corabia intră triumfal în port. Hoțul a intrat în casă prin efracție. Armata a intrat cu forța în oraș.

A se opri v. pron.

A rămâne undeva temporar, a zăbovi.

$$
\mathrm{N}_{1}+\mathrm{V}+\text { Circ }_{{ }_{\text {loc. }}}+\text { Circ }_{\text {timp. }} / .+ \text { Circ }_{\text {de scop. }_{\text {. }}}
$$

$\checkmark$ A se opri: într-un loc, la un han, într-un oraş / câteva zile, un timp, mai mult de o săptămână / pentru a încheia un contract.

- Ne-am oprit la un hotel o săptămână, pentru a vizita toate muzeele. Ne vom opri o zi la Braşov, pentru a vedea Biserica neagră.

Rezumând, se poate spune că predicația este o relație dintre funcția de identificare a ceea ce urmează să constituie conținutul enunțului, funcție proprie subiectului, și funcția de descriere, de caracterizare, proprie predicatului. Pentru a prezenta și a contura mai bine subiectul, verbul, folosit pentru exprimarea predicatului, antrenează toată gama de actanți, selectându-i pe cei strict necesari, obligatorii. Totuși, unele verbe au nevoie de elemente suplimentare pentru a reda plenar conținutul enunțului. Acestea sunt verbele cu predicație incompletă. De cele mai multe ori, aceste elemente se găsesc printre circumstanțe, care, de regulă nu fac parte din complinirile obligatorii ale verbului. Mai frecvent apare circumstanțialul de loc, urmat de celelalte circumstanțiale. 


\section{Referințe bibliografice:}

1. BĂRBUȚĂ, Ion. Structura prasgmasemantică a enunțului din limba română, Chișinău, 2012.

2. COȘERIU, Eugen. Solidaritățile lexicale. În: Philologia, 2021, nr. 1, p. 7-17.

3. CONSSTANTINOVICI, Elena. Circumstanțele și structura actanțială a verbului. În: Omagiu lui Ion Dumbrăveanu la 70 de ani. Chișinău, 2009, p. 239-244.

4. SANDULESCU, C. George, VIANU, L. Gramatica limbii engleze, București, 2011. Volumul 4 -Verbul- de Ioan Aurel Preda. p. 351-352.

Notă: Articolul a fost realizat în cadrul proiectului de cercetare 20.80009.1606.01 Valorificarea științifică a patrimoniului lingvistic național în contextul integrării europene, Institutul de Filologie Română „B. P.-Hasdeu” al MEC. 